Etnográfica

Revista do Centro em Rede de Investigação em

Antropologia

vol. $20(3) \mid 2016$

Vol. 20 (3)

\title{
Cláudia Sousa's parallel efforts in the laboratory and in the field: from the use of tokens by captive chimpanzees to the ontogeny of wild chimpanzee tool use
}

Os esforços paralelos de Cláudia Sousa no laboratório e no terreno: do uso de tokens por chimpanzés em cativeiro à ontogenia do uso de ferramentas por chimpanzés em habitat natural

\section{Tetsuro Matsuzawa and Dora Biro}

\section{(2) OpenEdition}

1 Journals

\section{Electronic version}

URL: https://journals.openedition.org/etnografica/4709

DOI: 10.4000/etnografica.4709

ISSN: 2182-2891

\section{Publisher}

Centro em Rede de Investigação em Antropologia

\section{Printed version}

Date of publication: 1 October 2016

Number of pages: 641-644

ISSN: 0873-6561

\section{Electronic reference}

Tetsuro Matsuzawa and Dora Biro, "Cláudia Sousa's parallel efforts in the laboratory and in the field: from the use of tokens by captive chimpanzees to the ontogeny of wild chimpanzee tool use", Etnográfica [Online], vol. 20 (3) | 2016, Online since 27 November 2016, connection on 11 February 2022. URL: http://journals.openedition.org/etnografica/4709; DOI: https://doi.org/10.4000/ etnografica.4709

\section{(c) (1) \$}

Etnográfica is licensed under a Creative Commons Attribution-NonCommercial 4.0 International License. 


\title{
Cláudia Sousa's parallel efforts in the laboratory and in the field: from the use of tokens by captive chimpanzees to the ontogeny of wild chimpanzee tool use
}

\section{Tetsuro Matsuzawa and Dora Biro}

\begin{abstract}
Cláudia Sousa was one of a handful of researchers that conducted studies on chimpanzee tool use and cognition in the wild and in the laboratory. Her main contributions to better understand chimpanzee cognition are presented here.

KEYWORDS: chimpanzees, great ape cognition, tool use, social learning.

Os esforços paralelos de Cláudia Sousa no laboratório e no terreno: do uso de tokens por chimpanzés em cativeiro à ontogenia do uso de ferramentas por chimpanzés em habitat natural - Cláudia Sousa foi uma das investigadoras que desenvolveu trabalho sobre o uso de ferramentas por chimpanzés, quer em contexto de habitat natural, quer em laboratório. Apresenta-se aqui uma resenha dos seus principais contributos para o estudo da cognição dos chimpanzés.
\end{abstract}

PALAVRAS-CHAVE: chimpanzés, cognição dos grandes símios, uso de ferramentas, aprendizagem social.

MATSUZAWA, Tetsuro (matsuzawa.tetsuro.8w@kyoto-u.ac.jp) - Primate Research Institute, Kyoto University, Japan.

BIRO, Dora (dora.biro@zoo.ox.ac.uk) - Department of Zoology, Oxford University, UK.

THIS PAPER COMBINES TWO TALKS PRESENTED AT THE CONFERENCE by the authors: "Tokens and tools: a parallel effort of lab work and fieldwork by Cláudia Sousa", by Tetsuro Matsuzawa, and "Learning to use tools: ontogeny of chimpanzee nut-cracking and leaf-folding at Bossou", by Dora Biro. This pair of talks highlighted Cláudia Sousa's contributions to the study of chimpanzee cognition, both in the field and in the laboratory, with a specific focus on tool use. The tools Cláudia studied ranged from the more abstract (coins) to those physically involved in obtaining food (stones to crack nuts) or water (clumps of leaves as drinking tools). Her studies covered a diverse range 
of topics including physical cognition, social learning, laterality, and cognitive development. ${ }^{1}$

During her PhD, Cláudia studied the use of tokens by chimpanzees as "secondary rewards", exchangeable for selected food items (Sousa and Matsuzawa 2006). In that sense, the tokens served as "tools" to obtain items of value for the chimpanzees. In the course of this research, Cláudia's observations revealed a number of interesting phenomena. For example, chimpanzees spontaneously developed "saving" behaviour: they accumulated several tokens, obtained through performing matching-to-sample tasks on a touch-sensitive monitor, before cashing them in at a computerised vending machine for food rewards (Sousa and Matsuzawa 2001). In addition, Cláudia observed a fascinating case of social learning from mother to offspring: chimpanzee Ai's son, Ayumu, at the age of two years and three months, spontaneously began to perform the full sequence of the token task by himself, after having accompanied his mother to the experiments since his birth (Sousa, Okamoto and Matsuzawa 2003). Although Ai never actively engaged in instructing Ayumu in the various different components of the task, she did allow him access to the apparatus and even to scrounge food rewards she had obtained herself. These results reveal numerous novel insights into chimpanzees' capacities for token use, as well as the mechanisms through which young chimpanzees learn novel skills through the long-term observation of conspecifics.

By adding an extra step to the process - a key "bought" in exchange for a token, which could be used to open a box containing a highly prized food item - Cláudia also showed that chimpanzees were capable of using secondary tools (Sousa and Matsuzawa 2006). To buy the key, chimpanzees had to first solve a matching-to-sample task to receive a coin, then use that coin in the vending machine and select the key as the item to be delivered, and then finally use the key on the locked box containing the food. This capacity demonstrated that chimpanzees were able to forego food of lower value (also available on the vending machine, pitted against the key) in order to obtain a higher value one.

As another extension of this work, Cláudia also established a novel technique for measuring food preferences in chimpanzees (Sousa 2003). After obtaining a token, chimpanzees had the option of choosing between two different foods in exchange for the token. By pitting two of a large set of different foods against each other in various combinations, and recording which of each pairing chimpanzees chose, she was able to construct a hierarchy of preferences. Of the different foods on offer, the one chimpanzees appeared to prize the most were blueberries.

1 A video archive with clips honouring Cláudia's research both in the laboratory and in the wild can be found on the Primate Research Institute (Kyoto University) website: http://langint.pri.kyoto-u. ac.jp/ai/en/claudia/. 
In the wild, Cláudia studied chimpanzee tool use at Kyoto University's long-running field site at Bossou, Guinea, West Africa. Her principal focus was the use of leaves for extracting water from tree holes for drinking, but she also contributed extensively to detailed observations of percussive stone tool use in nut-cracking.

Bossou chimpanzees use a clump of leaves they fold up in the mouth into a concertina-like shape, which they then insert into tree holes containing water. Cláudia carried out long-term observations of this behaviour at Bossou's "outdoor laboratory" (Matsuzawa 1994). Her research revealed the time-course of development in young chimpanzees, pinpointing the ages at which individuals acquire the different phases of the task (tool manufacture and tool use). Interestingly, young chimpanzees first perform leaf-tool use (at the age of around one year and a half) with tools manufactured, used then discarded by other individuals, and only later (around the age of three and a half years) do they begin to manufacture their own (Sousa, Biro and Matsuzawa 2009).

This reliance on others' abandoned tools is also evident in the development of nut-cracking. Young chimpanzees preferentially re-use stone tools left behind by adults, and such re-use brings about an increase in their nut-cracking efficiency (Biro et al. in prep.). It is a tantalising possibility that in both leaf-tool use and nut-cracking young individuals acquire important information about the physical demands of the tasks, and about the properties of "good" tools made or selected by proficient users, through interacting with these objects once they are discarded by adults. Thus, while adults do not engage in active teaching of their young, through their performance of the behaviours within view of learners, through their tolerance for being closely observed, and through leaving behind objects that can guide learning, they provide a rich "educational" environment that promotes acquisition in young (Matsuzawa et al. 2001).

To study how leaf-tool use efficiency increases in young learners, Cláudia measured the amount of water that leaf tools made by chimpanzees of different ages could carry. She did this by collecting leaf tools for which she could identify the user, repeatedly dipping the tool in water, and measuring the quantity of liquid thus retrieved. The results showed that both leaf-tool size and efficiency increase with age (Sousa, Biro and Matsuzawa 2009; Biro, Sousa and Matsuzawa 2006). This echoes findings in the study of nut-cracking development, where older chimpanzees have been shown to require increasingly fewer strikes of the hammer to open a single nut (Biro et al. 2003).

Observations of "handedness" (individual-level consistency in the identity of the hand used to manipulate a tool) showed some interesting contrasts between leaf-tool use and nut-cracking. Whilst chimpanzees are 100\% lateralised in their hammering at the individual level (beyond the first year when they acquire the behaviour, each individual relies exclusively on the left or the right hand to hold the hammer stone; Biro et al. 2003), in leaf-tool use they are 
considerably more ambidextrous (Sousa, Biro and Matsuzawa 2009). Cláudia explained this pattern by suggesting that leaf-tool use more often involves varying constraints imposed by the context in which the behaviour takes place: having to support the body with one hand whilst dipping for water in a tree means that the hand that is free to manipulate the tool will depend on where suitable branches for support are located. These studies thus reveal a range of interesting aspects of how both the social and the physical environment shape the acquisition and performance of important skills in chimpanzees.

\section{REFERENCES}

BIRO, Dora, Cláudia SOUSA, and Tetsuro MATSUZAWA, 2006, “Ontogeny and cultural propagation of tool use by wild chimpanzees at Bossou, Guinea: case studies in nut-cracking and leaf-folding", in Tetsuro Matsuzawa, Masaki Tomonaga and Masayuki Tanaka (eds.), Cognitive Development in Chimpanzees. Tokyo, Springer, 476-508.

BIRO, Dora, et al., 2003, "Cultural innovation and transmission of tool use in wild chimpanzees: evidence from field experiments", Animal Cognition, 6: 213-223.

BIRO, Dora, et al., in prep., "Tool inheritance: stone-tool 'recycling' increases nut-cracking efficiency in wild juvenile chimpanzees".

MATSUZAWA, Tetsuro, 1994, "Field experiments on use of stone tools by chimpanzees in the wild", in Richard Wrangham et al. (eds.), Chimpanzee Cultures. Cambridge, MA, Harvard University Press, 351-370.

MATSUZAWA, Tetsuro, et al., 2001, "Emergence of culture in wild chimpanzees: education by master-apprenticeship", in Tetsuro Matsuzawa (ed.), Primate Origins of Human Cognition and Behavior. Tokyo, Springer, 557-574.

SOUSA, Cláudia, 2003, The Use of Tokens by Chimpanzees: Computer-Controlled Experiments as a Way of Assessing Chimpanzee Cognition. Kyoto, Kyoto University, PhD thesis.

SOUSA, Cláudia, and Tetsuro MATSUZAWA, 2001, "The use of tokens as rewards and tools by chimpanzees (Pan troglodytes)”, Animal Cognition, 4: 213-221.

SOUSA, Cláudia, and Tetsuro MATSUZAWA, 2006, “Token use by chimpanzees (Pan troglodytes): choice, metatool, and cost”, in Tetsuro Matsuzawa, Masaki Tomonaga, and Masayuki Tanaka (eds.), Cognitive Development in Chimpanzees. Tokyo, Springer, 411 -438. SOUSA, Cláudia, Dora BIRO, and Tetsuro MATSUZAWA, 2009, "Leaf-tool use for drinking water by wild chimpanzees (Pan troglodytes): acquisition patterns and handedness", Animal Cognition, 12: S1 15-125.

SOUSA, Cláudia, Sanae OKAMOTO, and Tetsuro MATSUZAWA, 2003, "Behavioural development in a matching-to-sample task and token use by an infant chimpanzee reared by his mother", Animal Cognition, 6: 259-267, available at < http://langint.pri.kyoto-u.ac.jp/ai/intra data/ClaudiaSousa/Behavioural_development_in_a_matching-to-sample_task_and_token_ use_by_an_infant_chimpanzee_reared_by_his_mother.pdf $>$ (last access October 2016). 